\title{
Elogio à filosofia: o que significa fazer filosofia? ${ }^{1}$ \\ Praise for philosophy: what does it mean to do philosophy?
}

STEFANO BUSELLATO² / ANNA MARIA LORENZONI³

Aos estudantes do Curso de Filosofia da

UNIOESTE - Toledo, e a todos aqueles que escolheram o mesmo capinar.

Tristes são os tempos nos quais a filosofia deve justificar a própria existência. Triste é o nosso tempo. Claro que houve piores. Lançando o olhar para eles, podemos perceber que, sempre que tendências despóticas e totalitárias se aproximam, a filosofia torna-se incômoda e ameaçadora. Desde o seu nascimento, a expulsão de Anaxágoras, a condenação à morte de Sócrates, Justiniano que, em 529, fechou a Academia platônica com a sua vida quase milenar. Então houve fogueiras, perseguições, fugas, prisões, censuras. E quando hoje ouvimos falar que a filosofia nada faz, que é inútil, improdutiva, é o mesmo ódio que se põe a falar com palavras diversas.

Diante de tais acusações, uma pessoa que está habituada a fazer filosofia não pode perceber nada além de uma ingenuidade, digamos, pré-filosófica, que seria igualmente capaz de questionar qual é a utilidade da arte, dos sabores, do pensar, da música. Ou de um beijo. E de julgar um desperdício de recursos o fato de a vida ser em cores, ao invés de apenas em preto e branco. Mas não é só isso. É possível retorquir ao dedo em riste que nos intima do banco de acusação a responder à pergunta: "o que significa fazer filosofia?".

Faz-se necessário, porém, um esclarecimento preliminar: a pergunta levantada não pode ser satisfeita por meio de uma definição normal, um rótulo de dicionário a ser fixado pelo mero prazer da classificação. Isso não se deve a algum defeito da atividade filosófica, a sua inconsistência ou a sua nebulosidade; pelo contrário, devese isso à sua especificidade, pois a filosofia é precisamente outra coisa. Escreve Hegel (1995, §1, p. 39): “A filosofia não tem a vantagem, de que gozam as outras ciências, de poder pressupor seus objetos como imediatamente dados pela representação; e também como já admitido o método do conhecimento - para começar e para ir adiante". Ou seja, a filosofia deve construir inteiramente a partir de si mesma tanto o próprio objeto quanto o próprio método. Por esse motivo é que não pode recair sobre ela uma definição unívoca e objetivante que a feche por inteiro. Existem tantas

\footnotetext{
${ }^{1}$ Texto original em italiano traduzido ao português pela referida coautora.

2 Professor Visitante da UNILA, Campus de Foz do Iguaçu e ex-professor do Curso de Pós-Graduação em Filosofia da UNIOESTE. E-mail: stefano.busellato@email.it; stefano.busellato@gmail.com.

32Doutora, mestre e graduada em Filosofia pela Universidade Estadual do Oeste do Paraná UNIOESTE. Atua na linha de pesquisa de Ética e Filosofia Política. Atualmente, dedica-se ao estudo da obra de Ernst Bloch, sobretudo seus aspectos éticos e políticos e sua recepção na América Latina. E-mail: annamlorenzoni@gmail.com.
} 
filosofias quanto existem filósofos. O particular, nesse caso, antecede e forma o geral. Por isso, também os filósofos que não nasceram filósofos entraram na filosofia fazendo filosofia. E hoje os lemos como protagonistas do pensamento. A filosofia não é, a filosofia se faz. Ou, como escreveu Wittgenstein (1994, 4.112), "a filosofia não é uma doutrina, mas uma atividade [Tätigkeit]”.

Mais precisamente, a filosofia é uma área de atividade, cujas fronteiras são líquidas e sempre móveis. Isso, contudo, não é sinônimo de indistinção, tampouco de caos, pois a área do filosofar se alarga, se contrai e se desloca incessantemente em um plano desenhado por duas diretrizes específicas: a abscissa dos problemas e a ordenada do múltiplo.

Problema é uma palavra grega (proballein, lançar para frente), que significa protuberância, impedimento, obstáculo. Durante o alvorecer da nossa filosofia, o termo era utilizado para "colocar um enigma". Com o Organon de Aristóteles, passa a indicar a "formulação de uma investigação". Ao longo de nosso caminho, encontramos problemas, algo que dificulta a passagem, que chama a nossa atenção e que pede para ser observado, pensado, compreendido: aqui reside o início do filosófico. Que seja maravilha [thaumazein], como Platão queria, ou inquietação [uneasiness], de acordo com Locke, perceber como um enigma aquilo que está à nossa frente e sentir o impulso em direção à investigação que impele a interpretar a essência (ti estin?) significa que o nosso caminho se adentrou na área da atividade filosófica: a filosofia, escreve Schopenhauer (2015, Cap. 34, p. 487), "se apresenta como a tentativa da razão de resolver por meios próprios e independentes de qualquer autoridade o problema da existência”. Cada um, então, atravessa a existência por um ângulo próprio de incidência pessoal: este é o múltiplo.

Múltiplos são os caminhos, múltiplos os problemas que nele se encontram na relação com o eu, com os outros ou com o outro. Humani nihil a me alienum puto diz o filosofar, cuja atividade abrange potencialmente todos os lugares, situações e nuances, das "coisas mais baixas" até o céu estrelado. Por isso, são múltiplas também as disciplinas filosóficas e infinitas as posições que podem ser assumidas no interior de cada uma delas.

Não há melhor representação disso do que a ideia de Leibniz subjacente à sua teoria das mônadas. Cada mônada participa do todo, cada uma delas o representa e o exprime a partir da própria perspectiva e com diferentes graus de conhecimento. $\mathrm{O}$ todo, porém, é apenas como conjunto das pluralidades de cada singularidade. Assim é o filosofar, uma multiplicidade de múltiplos, prospectivos e expressivos, cada um de uma parte que, junto às inumeráveis outras, forma aquilo que chamamos filosofia.

Disso deriva o que talvez se mostre como o aspecto de mais árdua compreensão aos que carecem de experiência filosófica: a filosofia não oferece a verdade. Se desejamos empregar verdade ao singular, o singular já está imerso no plural, sempre 
implicitamente inserido entre aspas. Por isso, frequentemente sentimos lançar a crítica de que a filosofia não passa de um contínuo dissídio consigo mesma, incapaz de chegar a um acordo até mesmo sobre qual é o seu próprio objeto, ou sobre como investigá-lo, ou sobre a finalidade de tal investigação.

Lançar tal reprimenda, entretanto, indica uma não compreensão do significado do múltiplo filosófico, pois, uma vez que o acordo venha a ser alcançado, neste preciso momento sairemos da área da atividade filosófica e nos encontraremos na casa da teologia, da dogmática, da escolástica.

Escolástica (seja ela qual for) significa possuir uma verdade que, pela sua essência, precede a investigação e não pode sofrer alterações a partir desta; a investigação tampouco é dotada da liberdade de chegar, como seu eventual resultado, ao abandono daquela verdade. Escolástica é repetição, fórmula, ritual, confirmação. Não por acaso, o ato de fundação do pensamento moderno, perpetrado por Descartes tem início com a recusa da escolástica aristotélico-tomista aprendida na escola jesuíta La Flèche. Já em suas primeiras linhas, o Discurso deixa-nos uma preciosa indicação: "meu propósito não é o de ensinar aqui o método que cada um deve seguir para bem conduzir sua razão, mas somente fazer ver de que maneira eu me esforcei por conduzir a minha" (DESCARTES, 1979. p. 30). Isso não difere daquilo que diz Zaratustra, personagem conceitual com o qual Nietzsche deseja exprimir o significado do próprio filosofar: "Este - é o meu caminho, - qual é o vosso?", assim respondo aos que me perguntam pelo "caminho". Pois o caminho - não existe!".

"Morrer pela "verdade". - Não nos deixaríamos queimar por nossas opiniões: não somos tão seguros delas; mas talvez o faríamos para podermos ter e alterar nossas opiniões". É uma das afirmações mais fortemente anti-ideológicas, antibarbáricas, antiobscurantistas. Iluminista, no sentimento magistralmente fixado por Kant no horaciano "sapere aude!", e semelhantemente identificado com nitidez por Foucault como natureza supra-histórica de toda investigação filosófica autêntica.

Mas Kant possui também o mérito de trazer à luz uma outra característica nodal da atividade filosófica. Chamou-a crítica. Para além do significado técnico kantiano, crítica, em grego, significa julgar. Compartilha a etimologia com critério - ou seja, o fundamento de toda divisão (de-cisão) sensata entre o sim e o não - e com krisis, termo pertencente à medicina hipocrática que indicava, no interior da progressão de uma doença, o momento decisivo no qual ela manifestava a sua direção rumo ao início da cura ou da conclusão extrema. Além disso, atesta-se também uma outra acepção do verbo krinein, bastante concreta, rural: era o movimento horizontal e vertical do peneirar com o objetivo de separar o joio do trigo.

A atividade filosófica é atividade crítica; preparação e refinamento do juízo; busca plúrima de um critério válido com o qual analisar as complexidades problemáticas; é a crise de um dado assumido antes de tê-lo interrogado e analisado; 
é o liberar-se da aceitação passiva do pre-conceito, peneirando o fluxo do suposto, do apressado, ou do infundado buscando separar o precioso do grosseiro.

Em última instância, toda a filosofia que importa é crítica, seja o átomo de Epicuro ou o infinito de Bruno, os idola de Bacon ou o more geometrico de Espinosa, o empirismo de Hume ou "o duro esforço do conceito" hegeliano e assim por diante, até o pathos do conhecimento de Nietzsche, a análise do ser de Heidegger, a negatividade de Adorno, a unidimensão de Marcuse, o rizoma de Deleuze e Guattari. A atividade filosófica, como crítica, é dissidente diante do óbvio, buscando libertarse do seu jugo. Formular filosoficamente um juízo significa, assim, distanciar-se do pre-juízo, do pre-conceito, que Platão chamava doxa, opinião - lembrando-nos que ter uma opinião significa habitar o nível mais ínfimo do conhecimento. A opinião é imediata, colhida sem cautela da calçada do acaso, e é aquilo que chamamos de "nossa" acreditando ser algo que dominamos, mas da qual, na verdade, não passamos de servos (servidão, de servare, conservar).

O juízo filosófico é o ponto de atracação de uma rota de libertação da servidão da doxa. Heidegger, em sua analítica existencial, descreveu perfeitamente essa permanência na doxa e em seus três aspectos principais: a falação (Gerede), que leva ao uso de palavras inúteis em questões fúteis; a curiosidade (Neugier), que dedica atenção primária àquilo que é menos do que secundário; a ambiguidade ou equívoco (Zweideutigkeit), que eleva a ignorância como um saber .

Para que seja capaz de conduzir do pre-juízo ao juízo, do pre-conceito ao conceito, a atividade filosófica exige demora, esforço, paciência, zelo. Mas o que ela oferece em troca é uma capacidade ampliada de orientar-se no caos existencial, ela permite que se siga a entrelaçada trama de problemas com competências específicas, a habilidade de perceber onde bifurcam-se as coisas que parecem homogêneas e onde se encontram aquelas que parecem distantes. Fazer filosofia é adquirir a competência técnica do amplo e do profundo, superior àquilo que a nudez cotidiana geralmente permite. Isso só é possível em virtude de uma exigência que a atividade filosófica implica para poder colocar-se em movimento: fazer filosofia é, acima de tudo, um exercício contínuo de escuta.

Ler um texto é saber escutar o que o autor quer dizer, escutar aquilo que um problema revela. Compreender significa acolher em nós uma visão que inicialmente não nos pertence. A compreensão filosófica é, antes de qualquer outra coisa, capacidade de escutar a voz alheia, e só depois dessa escuta é que pode ter início a outra e mais célebre característica da filosofia, qual seja, o diálogo.

Quando uma pessoa que dedicou a própria vida à filosofia nos vem a faltar, desaparece com ela uma biblioteca, uma agorà, um emaranhado de diálogos, vozes, juízos que foram atravessados por uma experiência pessoal e por ela devolvidos de uma forma irrepetível. Irrecuperável. Não só parentes e amigos sofrem essa perda, 
mas também o nível de compreensão e de ideação com o qual nos relacionamos com o existente, isto é, numa palavra, a nossa cultura.

Manter vivo o ciclo de inteligência crítica é a tarefa a ser realizada em uma faculdade de filosofia. Ela oferece aos próprios estudantes a aquisição de uma competência proteiforme, porém técnica, para escutar e dialogar com os textos, com os autores, com as questões (em linguagem especializada, a exegese), com o próprio ser e com a alteridade. Engana-se quem pensa que um curso de filosofia ensina uma "doutrina", operando - segundo a expressão de Freire - mediante uma "educação bancária”, na qual um conhecimento detido pelo docente é depositado no aluno. "O verdadeiro professor evitará impor, da sua cátedra, qualquer tomada de posição ao aluno, quer seja ela expressa ou sugerida”, escreve Max Weber (1982, p. 172), "saber expor os problemas científicos de modo tal que uma mente não-instruída, mas receptiva, os possa compreender e possa vir a refletir sobre eles de forma autônoma, é, para nós, a coisa decisiva" (WEBER, 1982, p. 159).

Saber formar uma ideia autônoma significa desenvolver o juízo crítico. E, ao observarmos mais de perto a natureza de um juízo crítico, dissipa-se também uma outra acusação que prontamente é dirigida à atividade filosófica, qual seja, a de que se trata irremediavelmente de pura abstração, um aglomerado de palavras que flutuam distantes da materialidade do real e da concretude do mundo. É uma história que ouvimos desde os tempos de Tales e da mulher trácia. A atividade filosófica, como o albatroz de Baudelaire, seria a de realizar voos admiráveis no céu da teoria, mas desajeitadamente incapaz de se movimentar na praticidade do cotidiano. $O$ fato de que a oposição entre teoria e prática não passaria de um "ditado popular" (Gemeinspruch) já havia sido clarificado por Kant, em 1793. Marx, em sua XI tese sobre Feuerbach, chega a defender que a filosofia é de tal modo prática ao ponto de poder transformar o mundo. Mas é Arendt que esclarece como é precisamente o juízo crítico, ou seja, o melhor desempenho da faculdade de julgar, que funde a teoria à prática, o pensar ao agir, representando "a misteriosa capacidade do espírito [the mysterious endowment of the mind], pela qual são reunidos o geral, sempre uma construção espiritual [a mental construction], e o particular, sempre dado à experiência sensível" (ARENDT, 1992, p. 55). Sem o juízo, o pensar permaneceria surdo, e o agir cego. "A irreflexão - a imprudência temerária ou a irremediável confusão ou a repetição complacente de "verdades" que se tornam triviais ou vazias parece ser uma das principais características do nosso tempo. O que proponho, portanto, é muito simples: trata-se apenas de refletir sobre o que estamos fazendo" (ARENDT, 2007, p. 13). Dito em versos: "quem pensa o mais profundo, ama o mais vivo" (Ibidem).

Se lançamos a devida atenção ao termo atividade, percebemos que aquela filosófica mostra ser precisamente o contrário da fuga da realidade cotidiana e das lutas sociais e políticas. Do mesmo modo, olhando para os filósofos que, mais do que 
todos os outros, colocaram a contemplação cognoscitiva como finalidade da meditação filosófica, nota-se como Espinosa compõe uma Ethica ou como Aristóteles está convencido de que o ser humano é zoon politikon, não autossuficiente, que tem, portanto, a necessidade de viver com outros seres humanos: "entendemos não aquilo que é suficiente para uma pessoa só, que leva uma vida solitária, mas que vive também para os seus pais, os seus filhos, sua esposa, e para os seus amigos e concidadãos em geral, visto que o homem é por natureza um ser político" (ARISTÓTELES, 1996, I, 7). A finalidade do pensamento abstrato, para Aristóteles, é que ele seja compartilhado com os próprios semelhantes, a tal ponto que, ele afirma, quem se retira do consórcio humano, quem é incapaz de entrar na comunidade, seja por sua autossuficiência ou porque não sente a necessidade dela [...] ou é uma besta ou um deus (ARISTÓTELES, 1996, VII, 1).

Uma confirmação extraordinária da tensão entre a atividade filosófica em direção à concretude da práxis nos é apresentada por aquele que, mais do que qualquer outro, louvou o valor do mundo das ideias. Platão, idoso, ao saber do interesse filosófico demonstrado pelo jovem tirano Diógenes, abandonou honras e conforto, decidindo enfrentar uma longa e perigosa viagem marítima de Atenas até Siracusa, não obstante já houvesse feito duas tentativas em vão com o pai, Diógenes, o velho, colocando, também naquelas ocasiões, a própria vida em risco - pois vislumbrou a possibilidade de transformar a própria filosofia em uma ação concreta. Ele que considerava que com esse pensamento e com essa ousada esperança, havia partido, pois teria me envergonhado muito se me descobrisse um homem bom apenas nas palavras e incapaz de traduzir em ato as próprias ideias.

Qual é, então, o sentido do juízo crítico como ação filosófica? Responder a isso é apreender o segredo que anima a atividade do filosofar em cada uma de suas manifestações: no fundo, dito com palavras simples, ela deseja atingir uma elevação qualitativa concreta da existência e do existente. Fazer filosofia é uma atração gravitacional em direção ao aprimoramento, numa tentativa de aumentar a densidade do tempo que percorremos e que nos percorre, de aprofundar o espaço que ocupamos no individual e no coletivo - e que Dilthey chama Weltverwobenheit, o entrelaçamento entre o si e o mundo.

A essência prático-rural do krinen, que peneira o joio do trigo, o juízo do préjuízo, o conceito do pré-conceito e enfrenta com o múltiplo e a perspectividade os problemas que se apresentam àqueles que sabem e que querem percebê-los, é o arar ao campo que nos é dado para reavivar as possibilidades e as potencialidades adormecidas. Sabendo que, como ocorre na natureza, o vento poderá transportar as sementes que conseguiremos fazer germinar em nosso jardim, assentá-las e fazê-las florir em um outro campo, distante daquele sobre o qual nasceram, perpetuando-se, por sua vez, em outros indiscerníveis futuros. 
Nesse implemento de vis existendi talvez esteja aquele sentimento peculiar que desde a antiguidade é testemunhado em conexão com a atividade filosófica. Os gregos chamavam-no felicidade [eudaimonia], os latinos plenitudo vitae, Espinosa laetitia, Hume pleasure. O prazer de ler, refletir, conhecer, compreender, de saber agir diferentemente. Vargas Llosa, peruano prêmio Nobel de literatura, escreveu: "Seríamos piores do que somos sem os bons livros que lemos, mais conformistas, menos inquietos e rebeldes, e o espírito crítico, motor do progresso, sequer existiria. Tal como escrever, ler é protestar contra as adversidades da vida. [...] se enraíza na sensibilidade e na consciência, transforma os cidadãos mais difíceis de manipular, de aceitar as mentiras daqueles que querem lhe fazer crer que entre grades, inquisidores e carcereiros vivem seguros e melhor" (LLOSA, 2021).

Nesse mesmo sentido, também Heidegger (1999, p. 40; 46) escreveu: “A filosofia representa uma das poucas possibilidades, e, às vezes, necessidades verdadeiramente autônomas e criadoras, das quais o homem dispõe em sua própria existência histórica [...] ou seja, uma das poucas coisas grandiosas das quais o homem é capaz".

Se, após tudo o que foi dito, ainda for pedido aos que se dedicam à atividade filosófica que se justifiquem, se estes ainda forem acusados de inutilidade, de falta de fundamento, de abstração, a filosofia oferece uma última resposta ao inquiridor: o sorriso - recordando as palavras de Nietzsche (2000, p. 14): "em certos casos, como diz o provérbio, só se permanece filósofo - calando-se”.

\section{Referências}

ARENDT, H. A vida do espírito: o pensar/ o querer/ o julgar. Rio de Janeiro: Relume-Dumará - Ed. UFRJ, 1992.

. A condição humana. Trad. Roberto Raposo. 10. ed. Rio de Janeiro: Forense Universitária, 2007.

ARISTÓTELES. Ética a Nicômaco. Tradução de Mário da Gama Kury. São Paulo: Abril Cultural, 1996.

DESCARTES, R. “Discurso do método”. In: Textos selecionados. Trad. B. P. Júnior e J. Guinsburg. 2. ed. São Paulo: Abril Cultural, 1979.

HEGEL, G.W.F. Enciclopédia das Ciências Filosóficas (1830). 1. Ciência da Lógica, 2. Filosofia da Natureza, e, 3. Filosofia do Espírito. Trad. Paulo Menezes. São Paulo: Loyola, 1995.

HEIDEGGER, M. Introdução à filosofia. Apresentação e tradução de Emmanuel Carneiro Leão. 4. ed. Rio de Janeiro: Tempo Brasileiro, 1999.

LLOSA, M. V. Texto integral do discurso por ocasião do Prêmio Nobel de Literatura, Estocolmo, Suécia, 7 de dezembro de 2010. Tradução de Maria das Graças Targino.https://www.gilbertogodoy.com.br/ler-post/elogio-a-leitura-e-a-literatura---mariovargas-llosa

NIETZSCHE, F. Humano, demasiado humano: um livro para espíritos livres. Trad. de Paulo César de Souza. São Paulo: Cia. das Letras, 2000. 
BUSELLATO, S.

SCHOPENHAUER, A. O mundo como vontade e como representação: suplementos aos quatro livros do primeiro tomo. (t. II). Trad. Jair Barboza. São Paulo: Unesp, 2015.

WEBER, M. Ensaios de sociologia. Trad. Waltensir Dutra. 5. ed. Rio de Janeiro, LTC, 1982.

WITTGENSTEIN, L. Tratactus logico-philosophicus. Trad. Luiz H. L. Santos. 2. ed. São Paulo: Edusp, 1994.

Submissão: 19. 04. 2020 / Aceite: 10. 05. 2020 